\title{
Theoretical and forensic implications of developmental studies of the DRM illusion
}

\author{
C. J. Brainerd • V. F. Reyna $\cdot$ E. Zember
}

Published online: 15 December 2010

(C) Psychonomic Society, Inc. 2010

\begin{abstract}
In the study of false memory, developmental research on the Deese-Roediger-McDermott (DRM) illusion has played a pivotal role in theory evaluation and forensic application. The extensive developmental DRM literature (55 experiments published in English-language journals) provided the first clear evidence that false memories can increase dramatically from early childhood onward, whereas traditional ideas about cognitive development predict steady declines. Similar increases have recently been reported in false memory for complex, realistic life events, using forensically oriented paradigms. Age improvements in the ability to connect meaning across words have been found to be necessary and sufficient for developmental increases in the DRM illusion. When the data of developmental DRM studies are combined with parallel findings from forensically oriented paradigms, the result is an existence proof that a principle used by the law to evaluate children's evidence is mistaken. According to that principle, children's versions of events are always more likely to be infected with false memories than those of adults, and hence, juries should give more weight to adults' versions of events.
\end{abstract}

Keywords Developmental reversals · Children's false memory $\cdot$ Fuzzy-trace theory · Forensic memory

Gallo (2010) has extended his earlier review of the DeeseRoediger-McDermott (DRM) literature (Gallo, 2006) to the domain of individual differences. He asked whether the DRM illusion (Deese, 1959; Roediger \& McDermott, 1995) can be generalized to individual differences in autobiographical false memory_especially to clinically interesting

C. J. Brainerd $(\bowtie) \cdot$ V. F. Reyna $\cdot$ E. Zember

Department of Human Development, Cornell University,

Ithaca, NY 14853, USA

e-mail: cb299@cornell.edu varieties, such as recovered memories of childhood sexual abuse, recovered memories of past lives, and beliefs in alien abduction. The answer, which may surprise some, is yes, to a degree, inasmuch as the illusion is elevated in people who display these and other types of autobiographical false memories. Crucially, the reason seems to be variation in some of the same processes that have been tied to the illusion in basic experimental work.

In this Progress Report, we continue extending DRM research into the realm of individual differences by focusing on the individual differences dimension that has generated by far the most research: differences in chronological age. With respect to the child-to-young-adult age range in particular, at the time of this writing at least 55 experiments have been published in English-language journals in which DRM performance was compared across age groups, a number that would probably double if work from non-peer-reviewed sources and other languages had been included. Those experiments, along with their key features and findings, are listed in Table 1. In the next section, we sketch a pair of enduring problems that motivated this work, followed in later sections by summaries of important findings, remaining questions, and reasons why the DRM paradigm will surely be a continuing focus of developmental research.

The problem: testing theoretical predictions that supply forensic existence proofs

Developmental studies of the DRM illusion have been motivated by two problems that are rendered virtually inseparable by the curious history of developmental work on false memory, one theoretical and one that grows out of concerns about the reliability of evidence in criminal law (Brainerd \& Reyna, 2005). We sketch them separately. 
Table 1 Published developmental studies of the deese/Roediger/McDermott illusion

\begin{tabular}{|c|c|c|c|c|c|}
\hline Articles & Age span & No Exp. & Memory tests tests & Key variables & Results \\
\hline $\begin{array}{l}\text { Anastasi, Lewis, and } \\
\text { Quinlan (2008) }\end{array}$ & 5-adult & 1 & recall/recog. & $\begin{array}{l}\text { child- and adult-normed normed } \\
\text { DRM lists }\end{array}$ & $\begin{array}{l}\text { age increases in false memory for } \\
\text { child and adult normed lists }\end{array}$ \\
\hline $\begin{array}{l}\text { Bouwmeester and } \\
\text { Verkoeijen (2010) }\end{array}$ & $7-12$ & 1 & recog. & $\begin{array}{l}1 \text { vs. } 2 \text { study trials per DRM list; } \\
\text { effects of gist memory gist } \\
\text { memory and recollection } \\
\text { rejection separated with latent } \\
\text { variables models }\end{array}$ & $\begin{array}{l}\text { age increases in false memory } \\
\text { greater with } 2 \text { studies than } 1 \text {; age } \\
\text { increases tied to variability in gist } \\
\text { memory but not variability in } \\
\text { recollection rejection }\end{array}$ \\
\hline $\begin{array}{l}\text { Brainerd, Reyna, and } \\
\text { Forrest (2002) }\end{array}$ & 5-adult & 3 & recall/recog. & strong vs. weak DRM lists & $\begin{array}{l}\text { age increases in false memory; } \\
\text { larger increases for strong lists }\end{array}$ \\
\hline $\begin{array}{l}\text { Brainerd, Holliday, } \\
\text { and Reyna (2004) }\end{array}$ & $7-14$ & 1 & conjoint recog. & $\begin{array}{l}\text { separation of familiarity \& } \\
\text { phantom recollection }\end{array}$ & $\begin{array}{l}\text { larger age increases in phantom } \\
\text { recollection than in similarity }\end{array}$ \\
\hline $\begin{array}{l}\text { Brainerd, Forrest, } \\
\text { Karibian, and } \\
\text { Reyna (2006) }\end{array}$ & $6-14$ & 3 & recall/recog. & $\begin{array}{l}\text { gist cuing; learning disability } \\
\text { disability; testing delay }\end{array}$ & $\begin{array}{l}\text { age increases in false memory on } \\
\text { immediate and delayed tests; gist } \\
\text { cuing eliminates age increases from } \\
11-14 \text { years; smaller age increases } \\
\text { for learning disabled children }\end{array}$ \\
\hline $\begin{array}{l}\text { Brainerd et al., } \\
(2008 b)\end{array}$ & $5-17$ & 1 & recog. & $\begin{array}{l}\text { gist cuing; } 1 \text { vs. } 3 \text { study trials } \\
\text { per DRM list }\end{array}$ & $\begin{array}{l}\text { age increases in false memory; gist } \\
\text { cuing increased false but not true } \\
\text { memory; repetition increased true but } \\
\text { not false memory; gist cuing reduced } \\
\text { age increases in false memory }\end{array}$ \\
\hline $\begin{array}{l}\text { Brainerd, Holliday, } \\
\text { Reyna, Yang, and } \\
\text { Toglia (2010) }\end{array}$ & 7-adult & 1 & recog. & $\begin{array}{l}\text { emotional valence \& arousal of } \\
\text { DRM lists manipulated factorially }\end{array}$ & $\begin{array}{l}\text { age increases in false memory; larger } \\
\text { age increases for negatively } \\
\text { valenced lists than positively } \\
\text { valenced lists; largest age increases } \\
\text { for negative-arousing lists }\end{array}$ \\
\hline $\begin{array}{l}\text { Carneiro et al. } \\
\text { (2009a) }\end{array}$ & $3-12$ & 2 & recall/recog. & $\begin{array}{l}\text { DRM lists with basic-level vs. } \\
\text { superordinate critical distractors }\end{array}$ & $\begin{array}{l}\text { age increases in false memory for } \\
\text { basic-level critical distractors, but } \\
\text { no age decreases for superordi- } \\
\text { nate critical distractors }\end{array}$ \\
\hline $\begin{array}{l}\text { Carneiro and } \\
\text { Fernandez (2009) }\end{array}$ & $4-12$ & 2 & recall/recog. & $\begin{array}{l}\text { slow vs. fast list presentation } \\
\text { warning vs. no warning }\end{array}$ & $\begin{array}{l}\text { age increases in false memory with } \\
\text { no warning but decrease with } \\
\text { warning; larger age increases in } \\
\text { false memory with fast than with } \\
\text { slow presentation }\end{array}$ \\
\hline $\begin{array}{l}\text { Carneiro et al. } \\
(2009 \mathrm{~b})\end{array}$ & 4-adult & 3 & recall/recog. & $\begin{array}{l}\text { DRM lists with easy vs. hard } \\
\text { to identify themes }\end{array}$ & $\begin{array}{l}\text { age increases in false memory; easy } \\
\text { to identify themes increase false } \\
\text { memory in children and } \\
\text { adolescents but decrease it in adults }\end{array}$ \\
\hline $\begin{array}{l}\text { Carneiro, } \\
\text { Albuquerque, } \\
\text { Fernandez, and } \\
\text { Esteves (2007) }\end{array}$ & 3-adult & 2 & recall/recog. & $\begin{array}{l}\text { DRM lists normed for each age } \\
\text { level; long vs. short lists }\end{array}$ & $\begin{array}{l}\text { age increases in false memory for } \\
\text { age-normed lists and for both list } \\
\text { lengths }\end{array}$ \\
\hline $\begin{array}{l}\text { Dewhurst and } \\
\text { Robinson (2004) }\end{array}$ & $5-11$ & 1 & recall & $\begin{array}{l}\text { separation of semantic from } \\
\text { phonological false memory }\end{array}$ & $\begin{array}{l}\text { age increases in semantic false } \\
\text { memory but decreases in } \\
\text { phonological false memory }\end{array}$ \\
\hline $\begin{array}{l}\text { Dewhurst, Pursglove, } \\
\text { and Lewis (2007) }\end{array}$ & $5-11$ & 1 & recog. & $\begin{array}{l}\text { DRM lists presented in story } \\
\text { contexts vs. standard } \\
\text { presentation }\end{array}$ & $\begin{array}{l}\text { age increases in false memory for } \\
\text { standard presentation but age } \\
\text { decreases for stories }\end{array}$ \\
\hline $\begin{array}{l}\text { Ghetti, Qin, and } \\
\text { Goodman (2002) }\end{array}$ & 5-adult & 1 & recall/recog. & short DRM lists only & no age change in false memory ${ }^{a}$ \\
\hline $\begin{array}{l}\text { Holliday, Brainerd, } \\
\text { and Reyna (2008) }\end{array}$ & $7-15$ & 1 & recall & $\begin{array}{l}\text { gist cuing; } 1 \text { vs. } 3 \text { study trials } \\
\text { per DRM list }\end{array}$ & $\begin{array}{l}\text { age increases in false memory; gist } \\
\text { cuing increases false memory at } \\
\text { all ages except } 15 ; 3 \text { study trials } \\
\text { decrease false memory at all age } \\
\text { levels }\end{array}$ \\
\hline $\begin{array}{l}\text { Holliday, Brainerd, } \\
\text { and Reyna, (2010) }\end{array}$ & $7-11$ & 1 & recog. & $\begin{array}{l}\text { DRM lists presented as word } \\
\text { fragments vs. standard }\end{array}$ & $\begin{array}{l}\text { ages increases in false memory in } \\
\text { the standard condition but age }\end{array}$ \\
\hline
\end{tabular}


Table 1 (continued)

\begin{tabular}{|c|c|c|c|c|c|}
\hline Articles & Age span & No Exp. & Memory tests tests & Key variables & Results \\
\hline & & & & $\begin{array}{l}\text { presentation; } 1 \text { vs. } 3 \\
\text { recognition tests }\end{array}$ & $\begin{array}{l}\text { decreases in the fragment } \\
\text { condition; false memory higher } \\
\text { following } 3 \text { tests than } 1 \text { test }\end{array}$ \\
\hline $\begin{array}{l}\text { Holliday and Weekes } \\
(2006)\end{array}$ & $8-13$ & 1 & recog. & $\begin{array}{l}\text { standard vs. phonological } \\
\text { DRM lists }\end{array}$ & $\begin{array}{l}\text { age increases in false memory for } \\
\text { standard lists but age decreases } \\
\text { for phonological lists }\end{array}$ \\
\hline $\begin{array}{l}\text { Howe, Cicchetti, } \\
\text { Toth, and Cerrito } \\
(2004)\end{array}$ & $5-12$ & 1 & recall/recog. & $\begin{array}{c}\text { maltreated vs. low-SES vs. } \\
\text { normal-SES children }\end{array}$ & $\begin{array}{l}\text { age increases in false memory; age } \\
\text { increases not affected by } \\
\text { maltreatment or SES }\end{array}$ \\
\hline Howe (2005) & 5-adult & 1 & recall & $\begin{array}{l}\text { directed forgetting vs. directed } \\
\text { remembering }\end{array}$ & $\begin{array}{l}\text { age increases in false memory; } \\
\text { directed forgetting lowers false } \\
\text { memory in children but not adults }\end{array}$ \\
\hline Howe (2006) & $5-11$ & 3 & recall & $\begin{array}{l}\text { picture vs. word lists; DRM vs. } \\
\text { categorized lists gist cuing }\end{array}$ & $\begin{array}{l}\text { age increases in false memory for } \\
\text { words but not pictures; equal age } \\
\text { increases for DRM and } \\
\text { categorized lists; gist cuing did } \\
\text { not affect false memory }\end{array}$ \\
\hline Howe (2007) & $8-13$ & 1 & recall/recog. & $\begin{array}{l}\text { standard vs. emotional } \\
\text { (negative-arousing) lists }\end{array}$ & $\begin{array}{l}\text { age increases in false memory for } \\
\text { standard and emotional lists; greater } \\
\text { age increases for emotional lists }\end{array}$ \\
\hline Howe (2008) & $5-11$ & 4 & recall & $\begin{array}{l}\text { DRM lists of words, } \\
\text { photographs, and line drawings }\end{array}$ & $\begin{array}{l}\text { age increases in false memory for } \\
\text { words but not line drawings and } \\
\text { some photographs }\end{array}$ \\
\hline $\begin{array}{l}\text { Howe, Gagnon, and } \\
\text { Thouas (2007) }\end{array}$ & 6-adult & 1 & recall/recog. & $\begin{array}{l}\text { bilingual subjects; presentation \& } \\
\text { test languages varied factorially } \\
\text { so that they match or mismatch }\end{array}$ & $\begin{array}{l}\text { age increases in false memory; for } \\
\text { recall, higher child false memory } \\
\text { when languages match but higher } \\
\text { adult false memory when languages } \\
\text { mismatch; for recognition, mismatch } \\
\text { always yields more false memory }\end{array}$ \\
\hline $\begin{array}{l}\text { Howe, Wimmer, } \\
\text { Gagnon, and } \\
\text { Plumpton (2009) }\end{array}$ & 5-adult & 3 & recall & $\begin{array}{l}\text { forward vs. backward associative } \\
\text { strength of lists; DRM lists vs. } \\
\text { categorized lists }\end{array}$ & $\begin{array}{l}\text { age increases in false memory; age } \\
\text { increases amplified by both types } \\
\text { of associative strength; age } \\
\text { increases for both types of lists }\end{array}$ \\
\hline $\begin{array}{l}\text { Khanna and Cortese } \\
\text { (2009) }\end{array}$ & 8-adult & 2 & recall & $\begin{array}{l}\text { semantic and phonological } \\
\text { DRM lists presented orally } \\
\text { vs. visually }\end{array}$ & $\begin{array}{l}\text { age increases in false memory for } \\
\text { visually presented lists only; age } \\
\text { increases for semantic but not } \\
\text { phonological lists }\end{array}$ \\
\hline $\begin{array}{l}\text { Lampinen, Leding, } \\
\text { Reed, and Odegard } \\
(2006)\end{array}$ & 6-adult & 2 & recog. & $\begin{array}{l}\text { blocked vs. random list } \\
\text { presentation; gist cuing vs. } \\
\text { uncued presentation }\end{array}$ & $\begin{array}{l}\text { age increases in false memory for } \\
\text { blocked but not random } \\
\text { presentation and for uncued but } \\
\text { not gist cued presentation }\end{array}$ \\
\hline $\begin{array}{l}\text { Metzger, et al. } \\
(2008)\end{array}$ & 7-adult & 3 & recall/recog. & $\begin{array}{l}\text { child- and adult-normed } \\
\text { DRM lists }\end{array}$ & $\begin{array}{l}\text { age increases in false memory for } \\
\text { child- and adult-normed lists }\end{array}$ \\
\hline $\begin{array}{l}\text { Odegard, Holliday, } \\
\text { Brainerd, and } \\
\text { Reyna (2008) }\end{array}$ & 11-adult & 1 & conjoint recog. & $\begin{array}{l}\text { gist cuing of correct vs. } \\
\text { incorrect DRM list themes }\end{array}$ & $\begin{array}{l}\text { age increases in false memory when } \\
\text { incorrect theme was cued; no age } \\
\text { increase when correct theme was } \\
\text { cued; age increases in false } \\
\text { memory were due to phantom } \\
\text { recollection and not similarity }\end{array}$ \\
\hline $\begin{array}{l}\text { Otgaar and Smeets } \\
(2010)\end{array}$ & 8-adult & 2 & recall & $\begin{array}{l}\text { deep encoding: survival, moving, } \\
\text { pleasantness }\end{array}$ & $\begin{array}{l}\text { age increases in false memory; larger } \\
\text { increases for survival encoding }\end{array}$ \\
\hline $\begin{array}{l}\text { Paz-Alonso, Ghetti, } \\
\text { Donohue, } \\
\text { Goodman, and } \\
\text { Bunge, (2008) }\end{array}$ & 8-adult & 1 & recog. & $\begin{array}{l}\text { fMRI measurement as subjects } \\
\text { respond to recognition tests }\end{array}$ & $\begin{array}{l}\text { age increases in false memory; age } \\
\text { increases associated with age } \\
\text { changes in activation in the } \\
\text { medial temporal lobes and the left } \\
\text { vetrolateral prefrontal cortex }\end{array}$ \\
\hline $\begin{array}{l}\text { Sugrue and Hayne } \\
\text { (2006) }\end{array}$ & 5-adult & 1 & recall/recog. & 7 word vs. 14 word DRM lists & $\begin{array}{l}\text { age increases in false memory for } \\
14 \text { word lists only }\end{array}$ \\
\hline
\end{tabular}


Table 1 (continued)

\begin{tabular}{|c|c|c|c|c|c|}
\hline Articles & Age span & No Exp. & Memory tests tests & Key variables & Results \\
\hline $\begin{array}{l}\text { Sugrue, Strange, and } \\
\text { Hayne (2009) }\end{array}$ & 10-adult & 1 & recall & 7 word vs. 14 word DRM lists & no age increases in false memory \\
\hline $\begin{array}{l}\text { Weekes, Hamilton, } \\
\text { Oakhill, and } \\
\text { Holliday (2007) }\end{array}$ & $9-11$ & 1 & recall/recog. & $\begin{array}{l}\text { children with normal vs. poor } \\
\text { semantic processing ability; } \\
\text { standard vs. phonological } \\
\text { DRM lists }\end{array}$ & $\begin{array}{l}\text { lower levels of false memory for } \\
\text { children with poor semantic } \\
\text { processing, on standard but not } \\
\text { phonological lists }\end{array}$ \\
\hline $\begin{array}{l}\text { Wimmer and Howe } \\
\text { (2010) }\end{array}$ & 7-adult & 2 & recog. & $\begin{array}{l}\text { standard vs. deep vs. shallow } \\
\text { encoding; divided vs. full } \\
\text { attention during encoding }\end{array}$ & $\begin{array}{l}\text { age increases in false memory } \\
\text { between } 7 \text { and } 11 \text {; levels of } \\
\text { processing and attentional } \\
\text { manipulations affect children } \\
\text { more than adults }\end{array}$ \\
\hline
\end{tabular}

${ }^{a}$ Ghetti et al. (2002) reported that DRM false memory increases with age, but Reyna et al. (2007) reanalyzed their data and found age invariance in false memory

${ }^{\mathrm{b}}$ Sugrue et al. (2009) reported no age trends in false memory, but their adult subjects displayed abnormally low levels of intrusions of critical distractors, as compared to DRM norms for adults (Roediger et al., 2001)

DRM, Deese-Roediger-McDermott; SES, socioeconomic status; fMRI, functional magnetic resonance imaging

Testing the developmental reversal prediction

The first is a counterintuitive proposal that was discussed by Ceci and Bruck (1998) and Brainerd and Reyna (1998) some years before the first developmental DRM work was published. At the time, a substantial literature had accumulated with other paradigms that revealed consistent declines in false memory between early childhood and young adulthood, a pattern that was thoroughly consistent with classical theories of cognitive development. However, these authors observed that fuzzy-trace theory (FTT) predicts that some important types of false memories will increase markedly during this age range, and it specifies conditions that should produce that pattern. With respect to those conditions, FTT's account of false memory (Brainerd \& Reyna, 2005; Reyna \& Brainerd, 1995) is an opponent-processes model, which posits that subjects store dissociated traces of the surface form of events (verbatim traces) and of the relations and patterns that connect them (gist traces). Processing verbatim traces supports true memories ("I drank a Coke at lunch") and suppresses false memories of related events ("I didn't drink a Sprite because I remember drinking a Coke"), whereas processing gist traces supports true memories ("I drank a Coke at lunch") and false memories ("I drank a Sprite at lunch"). Because verbatim and gist memory improve with development (e.g., Reyna \& Kiernan, 1994, 1995), there is an algorithm for identifying situations in which false memories ought to wax with age. This should happen when (1) false memories are supported by gist traces that are increasingly apt to be processed as development unfolds, and (2) such errors are hard to suppress using verbatim traces of related events (so that improvements in that sphere will be of limited assistance in controlling errors).

That false memory might increase appreciably between early childhood and young adulthood is so foreign to customary ideas about the direction of cognitive development that it is called a "developmental reversal" prediction. The DRM illusion was a perfect place to begin to evaluate the prediction, for two reasons. First, the developmental literature contains extensive data on children's limitations in remembering lists of semantically related words, much of which was reported during the heyday of research on semantic organization in recall (e.g., Bjorklund, 1987; Bjorklund \& Hock, 1982; Bjorklund \& Jacobs, 1985; Bjorklund \& Muir, 1988). When young children study such lists, although care is taken to ensure that they know the words' meanings, they typically fail to connect shared meanings among words, as indexed by poor performance on standard indexes of memory for semantic relations - such as superior recall of related versus unrelated lists, semantic clustering, and semantic transfer. For semantic relations such as taxonomy and synonymy, for instance, performance on such indexes often does not improve before early adolescence. ${ }^{1}$

Gallo (2010) remarked that the DRM illusion is "semantically driven" and that it is possible to be quite specific about its semantic structure. DRM lists are particularly rich in semantic relations between list words and the critical distractors/lures that measure false memory, and they are also rich in properties of individual words that are known to encourage the processing of semantic

\footnotetext{
${ }^{1}$ There are some subtleties here, about which it is important to be precise. It is not that young children are utterly unaware that, say, candy, pie, and cake are sweet or that cow, sheep, and dog are animals or that pants, shirt, and coat are clothing. They can demonstrate such awareness if directly questioned. However, if left to their own devices when studying a list of semantically related words, they apparently fail to connect such simple meanings across exemplars spontaneously because they usually are not above chance on standard indexes of memory for semantic relations (for reviews, see Bjorklund, 1987; Bjorklund \& Muir, 1988).
} 
relations (see Madan, Glaholt, \& Caplan, 2010; Paivio, 1969, 1979). In this connection, Brainerd, Yang, Howe, Reyna, and Mills (2008c) conducted a semantic analysis of the DRM list pool (Roediger, Watson, McDermott, \& Gallo, 2001). Following a methodology developed by Cann, McRae, and Katz (2006), they scored DRM lists for six common semantic relations between list items and critical distractors (antonymy, synonymy, entity relations, introspective relations, situational relations, and taxonomic relations; see $\mathrm{Wu} \&$ Barsalou, 2009). The results (see their Table 2) showed that across the lists, the mean number of semantic relations between a critical distractor and the 15 words on the corresponding DRM list is 14.62. Two semantic relations, situational and taxonomic, predominate: Roughly nine of the 15 words, on average, are related to the critical distractor in one of these ways. Recently, Cann, McRae, and Katz (2010) tied situational gist causally to DRM false memory. They constructed lists in which (1) critical distractors were the names of familiar situations (e.g., farm) and list words were the names of things that are found in those situations (e.g., barn, cow), but (2) mean backward associative strength (BAS) between list words and critical distractors was near-zero. False recognition levels for these lists did not differ from standard DRM lists with high mean BAS.

This brief excursion into the semantics of the DRM paradigm reveals why it was such a promising place to begin to evaluate the developmental reversal prediction: DRM lists are so imbued with interword semantic relations and so high on semantic properties that encourage the processing of such relations that the paradigm ought to be acutely sensitive to known developmental trends in semantic processing. Both parts of the algorithm for developmental reversals are therefore satisfied. [The second part is satisfied because it is difficult to suppress false recall/recognition of the critical distractor doctor, for instance, by retrieving verbatim traces of the list words ill, hospital, and nurse when subjects know that there were many other medical words on the list and doctor could easily be one of them (Gallo, 2004).]

Another theoretical motivation for testing the developmental reversal prediction had emerged by the time the first studies were published, in 2002. By then, Roediger et al.'s (2001) activation/ monitoring theory (AMT) had appeared, so developmental data could be used to contrast FTT and AMT. Such data yield good separation between the two theories because although FTT predicts age increases in the DRM illusion, AMT predicts the opposite, owing to known age trends in associative processing and source monitoring. As Gallo (2010) commented, AMT emphasizes associative activation (pre-existing associations from list words to critical distractors) as the process that stimulates the illusion and source monitoring as the process that suppresses it. Publications in the developmental field are available on both aspects. Whereas source monitoring improves considerably between early childhood and young adulthood (e.g., Foley \& Johnson, 1985; Foley, Johnson, \& Raye, 1983), the standard developmental view of associative processing is that "associative relations are an early form of semantic representation that changes minimally in development" (Bjorklund \& Jacobs, 1985, p. 600). For instance, Bjorklund (1987) pointed out in a review of the developmental literature on associative processing that (1) the same children who fail to show word-relatedness effects, clustering, and transfer when list words are semantically related do show such effects when list words are associatively related and that (2) word-association norms for children and adults are highly correlated. If AMT's suppressive process increases appreciably with age while its stimulative process is largely invariant, the prediction would have to be developmental declines in the illusion.

\section{Existence proofs for the law}

The desire to test counterintuitive predictions would not have spawned a literature as large as that presented in Table 1 were it not for a parallel applied impetus. One of the best kept secrets of criminal law is that the evidence that bears on guilt is mostly memory (Brainerd \& Reyna, 2005). Contrary to what is commonly supposed, physical/forensic evidence is rarely gathered in criminal cases, and even when it is, it may not be determinative (Horvath \& Meesig, 1996, 1998). The type of evidence that is left is what people say they remember. Such memory evidence is reported by witnesses, victims, suspects, and investigators in interviews, interrogations, telephone conversations, written or recorded statements, affidavits, depositions, and court testimony. The constitutional obligation of a jury is to render a verdict by judging the credibility of different sources of evidence, and because the evidence is mostly memory and often conflicts, deciding what to believe and what to discount entails applying common-sense maxims about how memory works (Brainerd \& Reyna, 2005).

Developmental DRM studies make contact with one of these maxims, which involves evidence provided by children. Historically, such evidence was rare in criminal cases, and indeed, it was long excluded by statute in most jurisdictions on the ground that children's memories are too prone to distortion - that their recollections are too apt to be false - to be trusted. That situation changed in the late 1970s and early 1980s, when government statistics suggested that child sexual abuse was exploding. Children are usually the only sources of determinative evidence in such cases, which means that these crimes generally cannot be prosecuted without their evidence (Ceci \& Bruck, 1995). Also, although there was some scientific substantiation of the idea that children's memories are too prone to distortion to be trusted (e.g., Binet, 1900), there was not an extensive experimental literature on this concept; in fact, there was barely any 
literature at all. Finally, some child memory-suggestion experiments that were designed to put this idea to the test seemed to show that children's memories could be quite resistant to distortion (Ceci \& Friedman, 2000).

Not surprisingly, statutory barriers began to fall, and increasingly, children's memory reports became sources of evidence in criminal cases (McGough, 1993) - not only in child abuse cases, but in any sort of crime to which they were witnesses. Ultimately, the admissibility of child evidence received federal sanction in Federal Rules of Evidence 601 (Committee on the Judiciary of the House of Representatives, 2006), which instructed juries to judge the credibility of children's evidence for themselves, just as they are obliged to do with other forms of evidence.

However, that leaves the question of just how reliable children's evidence is. Beginning with some influential experiments by Ceci, Ross, and Toglia (1987), a large literature has accumulated whose aim has been to answer this question (for reviews, see Bruck \& Ceci, 1999; Goodman \& Schaaf, 1997; Reyna, Mills, Estrada, \& Brainerd, 2007), . Following initial skirmishes over methodology and some unsavory confrontations between researchers and child advocacy groups, as documented in Doris (1991), a consensus formed around a particular pattern. What had been repeatedly found - primarily using paradigms such as post-event suggestion about the details of experienced or observed events, forced confabulation of such details, and spontaneous false memory for real-life events - is that false memory, whether of the suggested or spontaneous variety, declined during normal development. An often-stated version of this consensus (Bruck $\&$ Ceci, 1999) is that children are more susceptible to false memory than adolescents or adults and that early childhood is a period of acute susceptibility.

The take-home message was that although children's memories may not be as utterly untrustworthy as was thought in the days of statutory exclusion, the chances that key items of evidence are false memories increase as those who supply it become younger and younger. This provided juries with two rules of thumb with which to judge the credibility of children's evidence (Brainerd \& Reyna, 2005): (1) In cases in which children are the sole sources of determinative evidence, juries must weigh the fact that children are highly prone to false memories, and (2) in cases in which both children and adults are sources of determinative evidence, children's evidence should be given less weight because they are more susceptible to false memories. Since the 1990s, these generalizations have figured in countless of hours of expert testimony in cases in which evidence from children was presented. In fact, some courts have recently ruled that these generalizations have risen to the level of common-sense knowledge that the average juror understands and can be expected to apply (Brainerd, Reyna, \& Ceci, 2008a). The forensic role that the
DRM paradigm has played is to provide a simple, easy-touse task that generates robust, replicable data that cut much of the ground from under these generalizations, for the obvious reason that DRM false memory increases dramatically during child-to-adult development.

An immediate objection in some forensic circles, echoing criticisms of the DRM paradigm by recovered memory advocates that Gallo (2010) discussed, is that because the paradigm involves word lists, it is irrelevant to understanding the types of the false memories that infect legal evidence. Researchers have responded in three ways to this objection. First, although the notion that word lists are irrelevant to real-life memory distortion seems selfevident to many, it has often proved wrong empirically. For example, in the study of aging, it is well known (e.g., Petersen, 2004) that recall of short word lists is the best single instrument for diagnosing clinical memory conditions such as dementia and mild cognitive impairment. With respect to memory distortion in individuals with emotional disturbances, Rubin and Talarico (2009) pointed out that word lists produce emotional reactions that parallel those that are produced by real-life events and autobiographical memories. Second, there is a key element of commonality between the DRM task and the memory evidence in criminal cases (Brainerd et al., 2008a). A major reason why, to many, word lists seem foreign to real-life memory distortion is that meaning relations are prominent features of real-life events, but as we saw, when people attempt to remember the words on DRM lists, they are remembering items that are richly interconnected by meaning relations. Third, researchers have responded by determining whether age increases in false memory can also be detected with other paradigms that have two features: (1) They are more complex and realistic, and hence, their faceresemblance to events that are stuff of legal evidence is much higher, but (2) they satisfy the algorithm for developmental increases in false memory. Experiments of that type will be summarized later.

\section{Impact}

The DRM paradigm has had three major effects on the study of memory development. Clearly, it has stimulated a cottage industry of developmental studies (Table 1). Second, it has altered what has long been the modal view of the ontogenesis of false memory. Although that view is consistent with long-standing hypotheses about cognitive development, adequate theories must encompass the fact that false memory will sometimes decrease dramatically with age and sometimes increase dramatically (Ceci, Fitneva, \& Williams, 2010). There is general agreement that such theories will have to be opponent-processes models; that is, 
they will have to (1) specify processes that create false memories and processes that suppress them, (2) specify how those contrasting processes vary with development, and (3) make the relative contributions of those contrasting processes to different false-memory tasks so transparent that it will be easy to predict which tasks will produce which types of developmental trends.

Third, the DRM-inspired discovery that false memories that are commonplace in adults can be near-floor in children has stimulated a new step in the evolution of the law's views about the trustworthiness of children's memory reports. Those views have gone through four stages in the past four decades. During the first two of these, the law flip-flopped from regarding children's memory reports as so unreliable that it was appropriate to exclude them by statute to assuming that those reports were so reliable with respect to certain events (e.g., abuse and other forms of personal trauma) that they could be accepted without corroborating evidence (Ceci \& Friedman, 2000). During the third stage, a consensus formed around an intermediate position, although one that was closer to the first stage than the second. According to that position, children's memory reports can be reliable, but they are far more susceptible to distortion than those of adults (Brainerd \& Reyna, 2005). As a result of recent demonstrations of marked age increases in DRM false memory, this position no longer seems defensible, and the law's ideas about children's memory have entered a fourth stage in which more subtle and qualified principles are required. A fundamental constraint on those principles, one that is perhaps difficult for researchers to appreciate, is that they must be simple enough that jurors can readily apply them to assess the credibility of children's evidence. Principles that are too technical to be grasped by laypersons or too qualified to support differential credibility judgments about the evidence in typical cases hinder rather than help jurors and, hence, are worse than no principles at all.

\section{Trajectory}

The empirical yield of developmental DRM research can be organized around three broad objectives. The first was the production findings of sufficient breadth that the conclusion that memory for things that did not happen can increase with age achieved widespread acceptance in the scientific community. The second was to explain those increases by tying developmental variability in the DRM illusion to corresponding variability in specific processes that cause that variability. The third was forensic validity - namely, to determine whether false memory in more complex, realistic tasks also exhibits age increases when those tasks satisfy the algorithm.
Does false memory actually increase?

\section{Development $=$ chronological age}

Given that 53 of 55 experiments detected developmental increases in false recall and/or false recognition, there is no argument as to the basic trend. Although developmental increases had been predicted on theoretical grounds, more than the usual amount of empirical convincing was required, owing to the classical literature showing developmental decreases. The first two series of experiments showing age increases in false recall and false recognition were reported by Brainerd, Reyna and Forrest (2002) and Brainerd, Holliday and Reyna (2004), but their data were far from sufficient to stimulate general acceptance of the age-increase pattern. The issue was not long in doubt, however, as several follow-up experiments from multiple countries were published during the next 3 years. In particular, Howe (2005), Howe, Cicchetti, Toth, and Cerrito (2004), and Dewhurst and Robinson (2004) all reported such work. Whereas Brainerd et al.'s (2002, 2004) subject samples were from the USA, Howe et al.'s (2004) were Canadian, while those in the remaining two articles were from the UK. With respect to false recognition of critical distractors, Howe et al. (2004) found that such errors increased between the ages of 5 and 12. With respect to false recall of critical distractors, Dewhurst and Robinson (2004) and Howe (2005) found that these errors increased between the ages of 5 and 11, and Howe et al. (2004) found that they increased between the ages of 5 and 12. Although young adolescents were the oldest subjects in these studies, it was clear that false recognition and false recall must increase thereafter because the error levels at that age remained below adult norms (see also, Brainerd, Holliday, Reyna, Yang, \& Toglia, 2010; Howe, Gagnon, \& Thouas, 2007; Metzger et al., 2008).

All of the studies presented in Table 1, other than two, used an age definition of development, and taken together, they produced the following overall trends. When standard DRM tasks with lists of normal length (12-15 words) are administered, false recall and false recognition both increase during the child-to-young-adult age range, with larger increases between early childhood and adolescence than between adolescence and young adulthood and larger increases in false recall than in false recognition. In some of these studies, it was also found that the probability of false recall/recognition increased more than the probability of true recall/recognition; that is, the probability of falsely recalling/recognizing a DRM list's critical distractor increased more than the probability of correctly recalling/recognizing any list word (e.g., Brainerd et al., 2002, 2010; Lampinen, Leding, Reed, \& Odegard, 2006; Metzger et al., 2008). This particular finding has been less robust than the developmental reversal 
pattern itself, which not surprising as it depends on the relative rates of age change in both true and false memory.

\section{Development $=$ ability level}

Age is a global index of development. It is also possible to use narrower, ability-based indexes to compare subjects of the same age who differ in some specific ability (as measured by school achievement or psychometric instruments) and who are matched on various other variables (especially IQ). With the DRM illusion, there is a theoretical motivation for studying some ability differences rather than others. The original basis for predicting developmental increases is the notion that the illusion is caused by gist memories of semantic relations that are instantiated by DRM lists, together with the fact that formation of such memories improves throughout childhood and adolescence. An obvious test of that idea is to compare children of the same age who differ in semantic-processing ability but who do not differ in general intelligence. There are two ways to conduct such tests.

The first is to compare learning-disabled children to nondisabled children, with the two groups of subjects having been matched on factors other than their learningability classification. Children who receive a learningdisabled classification are typically reading- or languagedisabled, and a common finding about their memory performance is that they are deficient in processing semantic relations among items on word lists (see various chapters in Obrzut \& Hynd, 1991). It follows that such children ought to show reduced DRM false memory, a prediction that was confirmed by Brainerd et al. (2006) in a study of DRM recall in 7- and 11-year-old learningdisabled and nondisabled children.

The second approach is more surgical and involves comparing same-age children who perform differently on particular psychometric tests, but who are matched on general intelligence and other factors. That approach was implemented by Weekes, Hamilton, Oakhill, and Holliday (2007), who administered DRM tasks to groups of children who performed at their age norm on tests that tap the ability to process semantic relations between words (e.g., tests of reading comprehension) versus more than 1 year below their age norm, but did not differ in IQ or tests of nonsemantic verbal abilities. Levels of true recall were the same in the two groups, but as predicted, false recall was much higher in children with normal semantic processing than in children with low semantic processing. Thus, the latter children's recall was actually more accurate. Another feature of Weekes et al.'s (2007) research that has been echoed in subsequent experiments (e.g., Brainerd \& Reyna, 2007; Holliday \& Weekes, 2006) is that these differences in false memory were specific to semantically related DRM lists. When phonological DRM lists were administered (Sommers \& Lewis, 1999), no between-group differences in true or false recall were detected.

\section{Amplifying the age trend}

If the DRM illusion becomes more seductive with development, the question is, why? One pattern of findings that bears on this question is that age increases in the illusion are made more pronounced by increasing the semantic richness of DRM materials. That is what would be expected by the algorithm that predicted age increases in the first place: Children's more limited semantic-processing abilities means that they will be less affected by enrichment manipulations, leading to Age $\times$ Treatment interactions in which the DRM illusion develops more with treatments that enhance it (in adults) by increasing meaning content.

Such interactions were initially reported by Brainerd et al. (2002, 2006), who administered two types of DRM lists, strong and weak, and found that age increases in false memory were more pronounced for the former. Strong lists, which produce higher levels of false memory in adults, are semantically richer than weak ones because, on average, their critical distractors are more familiar and meaningful (Brainerd et al., 2008c), they supply more of the situational gist that has been causally linked to higher levels of false memory (Cann et al., 2006, 2010), and they have higher BAS levels (Roediger et al., 2001). Concerning the latter property, it has long been understood that semantic relatedness increases as associative relatedness (backward or forward) increases (Anisfeld \& Knapp, 1968; Grossman \& Eagle, 1970), and in DRM research, Brainerd et al. (2008c) found that 15 semantic properties of words are reliable covariates of BAS and forward associative strength (FAS).

Other semantic-enrichment manipulations that have been studied developmentally include adding negative emotional relations between list words and critical distractors (Brainerd et al., 2010; Howe, 2007), administering lists for which the critical distractors are the names of basic-level categories (Carneiro, Albuquerque, \& Fernandez, 2009a), administering longer DRM lists (Sugrue \& Hayne, 2006), administering DRM lists with more easily identified themes (Carneiro, Fernandez, \& Dias, 2009b), increasing the mean BAS between targets and critical distractors (Howe, Wimmer, Gagnon, \& Plumpton, 2009), and increasing the mean FAS between targets and critical distractors (Howe et al., 2009). Each of these manipulations amplified developmental increases in false memory.

What causes developmental increases in false memory?

So far, the data are consistent with the algorithm that predicted more false memory in adults than children, but 
they do not supply strong tests of it. The traditional formula for tying specific processes to age increases in some target behavior is to pursue a two-pronged necessity-sufficiency strategy (Glaser \& Resnick, 1972), the object of which is to reduce or erase those increases with manipulations that embody the processes that are thought to be responsible. The sufficiency prong focuses on younger subjects, who exhibit lower levels of the target behavior, while the necessity prong focuses on older subjects, who exhibit higher levels. The question about younger subjects is whether manipulations that support a process that they are presumed to lack cause the target behavior to increase - in which case it is said to be developmentally sufficient. The question about older subjects is whether manipulations that interfere with that same process cause the target behavior to decrease-in which case it is said to be developmentally necessary. When both prongs yield positive findings, the process is said to be developmentally necessary and sufficient.

This strategy can used to determine whether the ability to form meaning connections between words is necessary and sufficient for age increases in the DRM illusion by establishing (1) whether manipulations that prompt the formation of meaning connections in subjects who fail to make such connections spontaneously diminish age increases by strengthening the illusion more in younger subjects than in older ones and (2) whether manipulations that interfere with the formation of meaning connections in subjects who make such connections spontaneously diminish age increases by reducing the illusion more in older subjects than in younger ones. We summarize findings for examples of the two types of manipulations below, and as both have produced reliable effects, the ability to form meaning connections appears to be central to age increases in the DRM illusion. That conclusion should be not overgeneralized, however, and in particular, it does not rule out the possibility that other processes are also central to age increases.

\section{Necessity prong}

Our concern here lies with manipulations that interfere with the formation of meaning connections with DRM lists. Even the first few words of such lists (e.g., Navy, soldier, rifle, Air Force, ...) provide strong meaning-connection cues to subjects who are adept at making such links. With standard DRM lists, two ways to block the formation of meaning connections are (1) to direct processing away from words' semantic content toward non-semantic features, or (2) to somehow make the semantic relations among list words less salient while not interfering with the processing of the meaning content of individual words.

Two manipulations of the former sort have been studied developmentally, presenting DRM lists as word fragments rather than as whole words (Holliday, Brainerd, \& Reyna, 2010) and presenting DRM lists with accompanying pictures (Howe, 2006, 2008), both of which yielded patterns that are expected on theoretical grounds. ${ }^{2}$ Concerning these manipulations, it is well established in the adult literature that word fragments focus subjects' processing on orthographic features, whereas pictures focus their processing on visual appearance and associated imagery. With respect to word-fragment presentation of DRM lists, Holliday et al. (2010) found that, relative to standard presentation, fragments reduced false memory more in older subjects than in younger ones and, consequently, shrank developmental trends in false memory. Indeed, fragment presentation reversed the standard age-increase pattern. With respect to picture presentation, several experiments have been reported with adults in which DRM false memory was reduced when lists were presented with accompanying pictures (e.g., Schacter, Israel, \& Racine, 1999). In Howe's (2006, 2008) developmental studies, DRM lists were presented as printed words, as line drawings, or as color photographs to 5-, 7-, and 11-year-olds. In the word condition, false recall of critical distractors increased with age in the usual manner. However, false recall did not increase with age with line drawings, and it also did not increase with age with color photographs that depicted objects against heterogeneous backgrounds. Age increases vanished in the pictorial conditions because although the levels of false recall for 5- and 7-year-olds were comparable for the different presentation modalities, those of 11-year-olds were four- to fivefold higher for words.

In the adult literature, pictorial suppression of DRM false memory is usually attributed to the activation of a metacognitive editing operation on memory tests (the distinctiveness heuristic), rather than to interference with the processing of semantic information during list presentation. This interpretation is based on the finding that the suppression effect is usually reliable when the pictureword manipulation is executed between subjects but not when it is executed within subjects (Schacter et al., 1999). Although the between- versus within-subjects comparison did not figured in the above developmental studies, the

\footnotetext{
${ }^{2}$ A third manipulation of this sort, shallow-encoding instructions, has been investigated in a developmental DRM study by Wimmer and Howe (2010), but owing to a design anomaly, it did not produce interpretable results. When adults study DRM lists under shallow encoding instructions, false memory levels are reduced (Thapar \& McDermott, 2001; Toglia, Neuschatz, \& Goodwin, 1999). Wimmer and Howe's (2010) research, in contrast, produced equivalent levels of adult false memory with standard and shallow encoding. The standard procedure in levels-of-processing designs is to manipulate encoding instructions between subjects in order to avoid contamination from different types of processing. However, the subjects in Wimmer and Howe's (2010) research studied some DRM lists under standard instructions, other lists under shallow encoding instructions, and still other lists under deep encoding instructions.
} 
distinctiveness heuristic explanation of the suppression effect is compatible with the results of those studies.

Turning to the second approach to interfering with subjects' tendency to process semantic relations, one method of lowering the salience of such relations in adults has been studied developmentally, and it produced data that conform to theoretical prediction. This manipulation, which was introduced by McDermott (1996), makes it less obvious to subjects that there are semantic relations between list words by switching from the usual blocked method of presentation to random presentation. Instead of presenting all $12-15$ words of a given DRM list before moving on to the next list, the random method involves mixing together the to-be-presented lists and then presenting the words in random order. In adults, random presentation reduces false memory, relative to blocked presentation (Brainerd, Payne, Wright, \& Reyna, 2003; McDermott, 1996; Toglia, Neuschatz, \& Goodwin, 1999). Lampinen et al. (2006) studied this manipulation developmentally, comparing false recognition levels in 6- and 8-year-olds and in young adults under blocked versus random conditions. With blocked presentation, the (bias corrected) false-alarm probability for critical distractors increased steadily with age, from 0.29 to 0.40 to 0.55 . With random presentation, however, the false-alarm probability was virtually the same in adults as in 6 -year olds $(0.18$ versus $0.15)$. Note that, as in the just-mentioned picture and word-fragment manipulations, the usual developmental trend disappeared because random presentation suppressed the false memory of adults far more than it suppressed that of 6-year-olds.

\section{Sufficiency prong}

With DRM lists, there is a simple, direct method of stimulating the formation of meaning connections by children who understand the relevant semantic relations but do not make those links spontaneously. In the classical literature on the development of semantic organization in recall (see Bjorklund, 1987; Bjorklund \& Muir, 1988), it was reasoned that if young children do not exhibit semantic-relatedness effects (e.g., semantic clustering and transfer), they ought to begin to display those effects if they are cued to process meaning relations that they already understand (e.g., that coat, pants, shirt, and socks are all clothing) as they study the lists. Many experiments produced positive results with various forms of studyphase cuing, such as alerting children that upcoming lists would contain exemplars of familiar taxonomic categories, with the cuing being most effective for children who were old enough to be familiar with the concepts that were being exemplified but too young to process them spontaneously (e.g., Bjorklund, Miller, Coyle, \& Slawinski, 1997).
In that vein, Brainerd et al. (2006) introduced a semantic cuing task in which children were informed that each DRM list consisted of words with very similar meanings and that they should attempt to figure out how the words were similar as the list was presented. Short training lists were administered in which children had to identify familiar semantic relations between words. Following such cuing, 6-, 11-, and 14-yearold children studied and recalled DRM lists. There were two key findings. First, as compared to control children who did not receive cuing, false recall levels were higher in 6- and 11year-olds who were cued, but not in 14-year-olds. Second, in children aged between 6 and 11 years, increases in false recall were smaller in the cuing condition than in the control condition, and in children aged between 11 and 14 years, false recall increased in the control condition but not in the cuing condition.

Pre-study semantic cuing of DRM lists has subsequently been investigated in developmental studies by Brainerd, Reyna, Ceci, and Holliday (2008b), Holliday, Brainerd, and Reyna (2008), Lampinen et al. (2006), and Odegard, Holliday, Brainerd, and Reyna (2008). As a group, these experiments replicated Brainerd et al.'s findings and extended them in three ways: (1) by encompassing broader age ranges, (2) by producing gist-cuing effects for false recognition as well as false recall, and (3) by further demonstrating that gist cuing can completely eliminate developmental increases in the DRM illusion.

Another method of stimulating DRM meaning connections by children who fail to make those connections spontaneously was developed by Dewhurst, Pursglove, and Lewis (2007). These authors proposed that if age increases in the DRM illusion are due to limitations in children's processing of semantic relations, it should be possible to elevate such processing by presenting DRM lists in narrative contextsspecifically, by presenting list words as parts of sentences that form an overall narrative that reinforces list themes. Dewhurst et al. (2007) created narratives of this sort for eight lists that are known to produce large age increases in false memory. These lists were administered to 5-, 8-, and 11-year-olds, using standard presentation for half of the subjects and narrative presentation for the other half, followed by recognition tests. Under standard presentation, the (bias-corrected) false-alarm probability for critical distractors increased steadily with age, from 0.41 to 0.58 to 0.65 . Under narrative presentation, this probability did not increase in children between ages 5 and 11 years because, like the gist cuing technique, narrative presentation increased false memory in younger but not in older children.

\section{Summary}

The necessity and sufficiency prongs have both produced positive findings. On the necessity side, manipulations that 
direct processing away from the semantic content of DRM lists and a manipulation that makes meaning connections among list words less obvious have been found to deflate developmental trends in false memory by reducing false memory more in older than in young subjects. On the sufficiency side, two manipulations that support the formation of meaning connections with DRM lists have been found to deflate developmental trends in false memory by increasing false memory more in younger than in older subjects. Thus, there is a good empirical case for the view that improvements in the ability to connect meaning across words are necessary and sufficient for developmental increases in the DRM illusion. As mentioned earlier, however, this conclusion should not be over generalized and interpreted as somehow ruling out contributions from other processes.

\section{Postscript on word familiarity}

The empirical case that improvements in the ability to connect meaning across words are necessary and sufficient for developmental increases in the DRM illusion is subject to a potential ambiguity about word knowledge. Semantic relations are instantiated by words in this task, and thus, these relations can only be processed to the extent that subjects understand the words. (We would not expect these relations to be processed by unilingual adult speakers of languages other than English, for instance.) Many of the words on DRM lists might be too unfamiliar to children for them to connect meaning across those words, even though they may have no difficulty doing so for words that are familiar to them. According this explanation, developmental increases in word familiarity cause the illusion to strengthen - and do not represent growth in the ability to connect meaning.

This explanation has been examined and rejected in multiple experiments. Early on, Brainerd et al. (2002) pointed out that DRM lists are composed of words that are among the most familiar ones in the English language. To illustrate, on the 7-point scale of familiarity in Toglia and Battig's (1978) semantic word norms, the mean of the words on the 55 lists in the Roediger et al. (2001) pool is 6.23. Second, Brainerd et al. (2002) compared children's levels of false memory for DRM lists that contain a few moderately unfamiliar words (none contain rare words) versus lists that do not. False recognition and false recall did not differ for the two types of lists.

A more subtle version of this explanation appeals to developmental differences in semantic relations between words, as indexed by word-production norms. DRM lists are constructed by selecting forward associates of unpresented words from adult production norms (Nelson, McEvoy, \& Schreiber, 1999; Russell \& Jenkins, 1954). If the words that children provide when they are asked what words come to mind when they hear, say, doctor or window, are different than those that adults provide, the meanings in which doctor and window participate are demonstrably different for children. It follows that if children are exposed to the adult-generated doctor or window list, the semantic connections between these unpresented words and the list words will not be as strong as when children are exposed to child-generated lists. According to this explanation, then, what causes the DRM illusion to strengthen is that with adult-generated lists, the semantic connections between list words and unpresented words will be inherently stronger for adults than for children. The prediction is that the illusion will increase with age (in the usual way) when adult-generated lists are administered to all age levels but (1) will decrease with age when child-generated lists are administered to all age levels and (2) will not vary with age when the lists administered to each age level were generated by subjects at that age level.

All tests of these predictions have disconfirmed this premise. Concerning (1), Anastasi, Lewis and Quinlan (2008) and Metzger et al. (2008) tested this prediction, with subjects ranging from 5 years of age to their early 20 s. Rather than decreasing with age, the DRM illusion increased with age with child-generated as well as adultgenerated lists. Concerning (2), Carneiro, Albuquerque, Fernandez, and Esteves (2007) tested this prediction with 4-, 7-, 12-, and 24-year-olds and, contrary to prediction, false recall and false recognition both increased with age with lists that had been separately generated by each age level. These increases were confined to the 4- to -7-year age range, from which it is tempting to conclude that although the hypothesis that increases in the DRM illusion are entirely due to developmental changes in word meaning is wrong, those changes nevertheless contribute some of the variance to age increases in the illusion. Carneiro et al.'s (2007) data actually do not support such a conclusion, owing to a restricted-range problem with their adultgenerated lists: These lists produced much lower levels of false memory with Portuguese-speaking adults than the DRM lists that have been used in most of the studies in Table 1 produce with English-speaking adults; statistical power to detect age increases is far weaker with the Portuguese lists.

A final methodological point merits brief comment. Because the DRM illusion is correlated with the total BAS between list words and critical distractors (Robinson \& Roediger, 1997), the data on Prediction (2) would not be determinative if the age-appropriate lists that were administered to different age levels varied in total BAS. However, lists were matched on this variable: The mean total BAS of the three different sets of lists that Carneiro et al. (2007) administered to their 4-, 7-, and 12-year-olds was 0.71 , and 
the corresponding value for the fourth set of lists that they administered to their adults was 0.72 .

Forensic significance of age increases in false memory

Developmental DRM research delivers an existence proof that some of the key assumptions used by the law to evaluate children's evidence are untenable. The knee-jerk response is that such research may not have broad implications because legal evidence involves memories of complex, realistic events, not word lists. To decide how broad the implications are, it is necessary to determine whether other paradigms that fit the algorithm but which are more forensically relevant also produce age increases in false memory. (By "fit the algorithm", we mean that false memories are supported by gist memories that are more apt to be processed as development proceeds and that it is hard to use verbatim traces of actual events to suppress false memories.)

Although many studies have been conducted with the Loftus (1975) misinformation paradigm in which false memories decreased with age, the standard version of this paradigm does not fit the algorithm that predicts age increases (Brainerd \& Reyna, 1998; Ceci \& Bruck, 1998). However, the standard paradigm can readily be adjusted to fit the algorithm by instantiating the meanings of objects/ events that are supplied to children as misinformation with many things that they actually experience during the initial phase of such an experiment, much like DRM lists. The surprising prediction, considering the large literature showing age decreases in susceptibility to misinformation, is that these false memories will now increase with age. Five articles have been published in which that adjustment was made, and all of them detected age increases in suggestion-induced false memory (Ceci, Papierno, \& Kulkofksy, 2007; Connolly \& Price, 2006; Fazio \& Marsh, 2008; Principe, Gauiliano, \& Root, 2008; Ross et al., 2006). We single out the Principe et al. (2008) and Ross et al. (2006) articles for special mention because both studied forms of suggestion that are common features of criminal cases.

Principe et al. (2008) investigated rumor mongering, which operates during the investigative phase of a case when gossip about the nefarious behavior of suspects circulates back and forth among witnesses (Brainerd \& Reyna, 2005). This can cause people to remember firsthand experiences of such behaviors when, in fact, they have only been exposed to hearsay reports. In their rumormonger study with 3- to 6-year-old children, Principe et al. found when such false memories required the formation of meaning connections (specifically, causal connections), they increased with age. Ross et al. (2006) studied false eyewitness identifications, which are the largest single source of false convictions in the USA according to the
Department of Justice statistics (Wells et al., 1998). They hypothesized that one reason that eyewitnesses are highly susceptible to suggestion is that they rely on gist memories of suspects' appearance ("young-thin-Hispanic-male"). If younger children are less likely to form such memories, they should be less susceptible to suggestions that innocent bystanders who fit the gist of culprits' appearance are, in fact, culprits. This is precisely what was found with groups of 5-, 7-, 9-, and 11-year-olds: Following suggestive questioning, the probability of falsely identifying innocent bystanders who matched culprits in age, build, gender, and ethnicity increased with age, from 0.18 to 0.40 to 0.47 to 0.64 , and the net accuracy of eyewitness identifications (total correct culprit identifications divided by total correct identifications plus total incorrect identifications) declined.

Turning to spontaneous false memory for complex, realistic events, three studies that fit the algorithm and show age increases in false memory have recently been reported. Fernandez-Dols, Carrera, Barchard, and Gacitua (2008) examined age trends in false memory for characters' emotional expressions, after subjects had viewed videos and slide sequences and received information that would allow them to form gist memories of characters' emotional states. They found that false recognition of gist-consistent emotional expressions increased by two-thirds between the ages of 6 and 9 years. Lyons, Ghetti, and Cornoldi (2010) examined age trends in false memory for scripted events (e.g., eating at a restaurant). They predicted that false memories would increase with age when errors required connecting meaning across events (e.g., making causal links) and found that there was actually a five-fold increase in that type of false memory between the ages of 6 and 18. Odegard et al. (2009) studied age trends in false memory for events that preserved the gist of four thematic birthday parties that children had attended. They found that false recognition of such events increased between the ages of 5 and 12 years.

\section{Closure}

That false memory would increase markedly with age is so surprising that experimentation has quite naturally focused on validating processes that could cause those increases, largely to the exclusion of whether suppressive processes that modulate the increases are developing at the same time. That this may be happening is more than idle speculation because, as Gallo $(2006,2010)$ documented, adults keep DRM errors somewhat in check via item-level suppression operations (disqualifying monitoring) and suppression operations that focus on classes of items that share some property that was not present in encoded materials (diagnostic monitoring). Although suppression is discussed 
in many developmental articles, the 55 experiments in Table 1 contain virtually no data on the question. Regarding item-level suppression, three experiments measured age variability in FTT's recollection-rejection operation. Brainerd et al. (2004) and Bouwmeester and Verkoeijen (2010) reported that it did not increase between early childhood and early adolescence, while Brainerd et al. (2004) and Odegard et al. (2008) reported substantial increases between early adolescence and young adulthood. Regarding disqualifying monitoring, the pre-study warning manipulation of Gallo, Roberts, and Seamon (1997) and the directed forgetting manipulation of Kimball and Bjork (2002) have been investigated (Carneiro \& Fernandez, 2009; Howe, 2005), but there seems to be only one developmental study of the most-researched suppression operation of this type in adults, Schacter and associates' (e.g., Schacter et al., 1999) distinctiveness heuristic, and the procedures of that study (Ghetti et al., 2002) differed in certain respects from those of Schacter et al. (Reyna et al., 2007). With such a paucity of data, fundamental questions such as the following remain unanswered: Do suppression operations contribute to development trends in the DRM illusion, or do they first emerge in young adulthood? If suppression operations contribute to developmental trends, when do they begin to do so? If suppression operations contribute to developmental trends, when are specific operations first used and is there any informative sequencing of those operations? [The slow developmental course of metacognition (Bjorklund, 2004) suggests that item-level operations would emerge before disqualifying operations (Brainerd et al., 2006).]

A second question that remains to be answered is that although we know a good deal about one process that stimulates the early growth of the DRM illusion (gist memory for inter-word meaning relations), other processes are surely involved. Some obvious possibilities that have been proposed are age improvements in working-memory capacity (Metzger et al., 2008), resistance to interference (Howe, 2005), strength of word associations (Howe et al., 2009), and word knowledge (Carneiro et al., 2007). Word knowledge has been rejected (see above), but research on the other aspects is thin to nonexistent. Automaticity of associations is the only one that has been the topic of focused experimentation, and here, the problem that variations in strength of word associations are confounded with variations in meaning relations (see above) has yet to be sorted out. This is all by way of saying that the identification of other processes that contribute to age increases in the DRM illusion is open territory.

A third unanswered question grows out of concerns about the accuracy of children's memory reports in legal cases - the raison d'etre of developmental studies of false memory. In the child forensic arena, the Holy Grail is simple, easy-to-administer instruments that are strong predictors of individual differences in false memory for everyday experiences, in subjects of different ages (see Scullin \& Ceci, 2001). The DRM task is simple, easy-toadminister, and produces robust age trends, all of which make it a most attractive candidate for forensic application. Other points in its favor are that (1) its connected-meaning property is a hallmark of everyday experience, and (2) false memories also increase with age when forensic memory tasks incorporate that property. However, a crucial piece of data is missing: When forensic tasks and the DRM paradigm are administered to subjects of different ages, is variability in the latter a strong predictor of variability in the former? The answer is as yet unknown because none of the studies in Table 1 included tasks such as, say, misinformation or eyewitness identification or the Gudjonsson (1984) forensic memory scale or autobiographical false memory [indeed, there is only a single adult study comparing DRM false memory to the Gudjonsson scale (Marche, Brainerd, \& Reyna, 2010) and only a single adult study comparing DRM false memory to autobiographical false memory (Qin, Ogle, \& Goodman, 2008)]. The results will determine the paradigm's broader applicability to child witnesses.

\section{Judgment}

The change that DRM research has wrought in our understanding of the early growth of false memory can hardly be overstated. The received wisdom that false memories steadily decline during child-to-adult development has been replaced by an appreciation that false memory can exhibit increases that are so pronounced that it can increase more than true memory. This appreciation is very recent, however, and has yet to penetrate beyond the memory development cognoscenti. The old assumption of developmental decline in false memory remains in full vigor in the clinical child psychology literature (e.g., Patterson \& Pipeb, 2009) and is still entrenched in the law (e.g., Bull, 2010; Neoh, \& Mellor, 2009). An important reason for continued developmental DRM research, then, beyond its track record of success in answering theoretical questions, is to ensure that this situation changes.

Here, developmental DRM studies with a transparently forensic slant will be vital; studies that link age changes in the illusion to age changes in traditional forensic memory tasks. Another important line of forensic investigation was just mentioned: Developmental DRM studies of suppression operations. Suppression operations are a cornerstone of forensic memory work, owing to the motivation to create best-practice protocols that reduce false memories and maximize true memories when interviewing and taking testimony from vulnerable witnesses, such as children (Ceci \& Bruck, 1995). Much effort has been invested in such 
protocols (see Brainerd \& Reyna, 2005), the working assumption being that false memories can be minimized and true memories maximized by (1) removing the suggestive tactics that often figure in police interviews and sworn testimony and (2) including cues to use specific suppression operations. The first objective is a feature of all scientific protocols for interviewing child witnesses (Poole \& Lamb, 1998). The second objective is more difficult to accomplish because it requires data showing which suppression operations children are able to use at which age levels. As we know from Gallo's $(2006,2010)$ reviews, the DRM paradigm has a proven track record in the study of both item-level suppression and disqualifying monitoring in adults, and thus, the paradigm should be enormously useful in generating developmental data on the two forms of suppression. It has yet to be exploited for this purpose.

\section{References}

Anastasi, J. S., Lewis, S., \& Quinlan, F. (2008). Examining differences in the levels of false memories in children and adults using child-normed lists. Developmental Psychology, 44, 889-894.

Anisfeld, M., \& Knapp, M. (1968). Association, synonymity, and directionality in false recognition. Journal of Experimental Psychology, 77, 171-179.

Binet, A. (1900). La suggestibilite. Paris: Schleicher Feres.

Bjorklund, D. F. (1987). How changes in knowledge base contribute to the development of children's memory. Developmental Review, 7, 93-130.

Bjorklund, D. F. (2004). Children's thinking: Cognitive development and individual differences. Belmont, CA: Wadsworth.

Bjorklund, D. F., \& Hock, H. H. (1982). Age differences in the temporal locus of memory organization in children's recall. Journal of Experimental Child Psychology, 33, 347-362.

Bjorklund, D. F., \& Jacobs, J. W. (1985). Associative and categorical processes in children's memory: The role of automaticity in the development of free recall. Journal of Experimental Child Psychology, 39, 599-617.

Bjorklund, D. F., Miller, P. H., Coyle, T. R., \& Slawinski, J. L. (1997). Instructing children to use memory strategies: Evidence of utilization deficiencies in memory training studies. Developmental Review, 17, 411-441.

Bjorklund, D. F., \& Muir, J. E. (1988). Children's development of free recall memory: Remembering on their own. Annals of Child Development, 5, 79-123.

Bouwmeester, S., \& Verkoeijen, P. P. J. L. (2010). Latent variable modeling of cognitive processes in true and false. Journal of Experimental Psychology: General, 139, 365-381.

Brainerd, C. J., \& Reyna, V. F. (1998). Fuzzy-trace theory and children's false memories. Journal of Experimental Child Psychology, 71, 81-129.

Brainerd, C. J., \& Reyna, V. F. (2005). The science of false memory. New York: Oxford University Press.

Brainerd, C. J., \& Reyna, V. F. (2007). Explaining developmental reversals in false memory. Psychological Science, 18, 442-448.

Brainerd, C. J., Payne, D. G., Wright, R., \& Reyna, V. F. (2003). Phantom recall. Journal of Memory and Language, 48, 445467.
Brainerd, C. J., Forrest, T. J., Karibian, D., \& Reyna, V. F. (2006). Development of the false-memory illusion. Developmental Psychology, 42, 662-679.

Brainerd, C. J., Holliday, R. E., \& Reyna, V. F. (2004). Behavioral measurement of remembering phenomenologies: So simple a child can do it. Child Development, 75, 505-522.

Brainerd, C. J., Holliday, R. E., Reyna, V. F., Yang, Y., \& Toglia, M. P. (2010). Developmental reversals in false memory: Effects of emotional valence and arousal. Journal of Experimental Child Psychology, 107, 137-154.

Brainerd, C. J., Reyna, V. F., \& Ceci, S. J. (2008a). Developmental reversals in false memory: A review of data and theory. Psychological Bulletin, 134, 343-382.

Brainerd, C. J., Reyna, V. F., Ceci, S. J., \& Holliday, R. E. (2008b). Understanding developmental reversals in false memory. Psychological Bulletin, 134, 343-382.

Brainerd, C. J., Reyna, V. F., \& Forrest, T. J. (2002). Are young children susceptible to the false-memory illusion? Child Development, 73, 1363-1377.

Brainerd, C. J., Yang, Y., Howe, M. L., Reyna, V. F., \& Mills, B. A. (2008c). Semantic processing in "associative" false memory. Psychonomic Bulletin \& Review, 15, 1035-1053.

Bruck, M., \& Ceci, S. J. (1999). The suggestibility of children's memory. Annual Review of Psychology, 50, 419-439.

Bull, R. (2010). The investigative interviewing of children and other vulnerable witnesses: Psychological research and working/professional practice. Legal and Criminological Psychology, 15, 5-23.

Cann, D. R., McRae, K., \& Katz, A. N. (2006). Knowledge types underlying backward associative strength and false recall in the Deese-Roediger-McDermott paradigm. Houston, TX: Paper presented at Psychonomic Society.

Cann, D. R., McRae, K., \& Katz, A. N. (2010). False recall in the DeeseRoediger-McDermott paradigm: The roles of gist and associative strength. Quarterly Journal of Experimental Psychology.

Carneiro, P., Albuquerque, P., \& Fernandez, A. (2009a). Opposite developmental trends for false recognition of basic and superordinate names. Memory, 17, 411-427.

Carneiro, P., Albuquerque, P., Fernandez, A., \& Esteves, F. (2007). Analyzing false memories in children with associative lists specific for their age. Child Development, 78, 1171-1185.

Carneiro, P., \& Fernandez, A. (2009). Age differences in the rejection of false memories: The effects of giving warning instructions and slowing the presentation rate. Journal of Experimental Child Psychology, 105, 81-97.

Carneiro, P., Fernandez, A., \& Dias, A. R. (2009b). The influence of theme identifiability on false memories: Evidence for agedependent opposite effects. Memory \& Cognition, 37, 115129.

Ceci, S. J., \& Bruck, M. (1995). Jeopardy in the courtroom. Washington, D.C.: American Psychological Association.

Ceci, S. J., \& Bruck, M. (1998). The ontogeny and durability of true and false memories: A dual trace account. Journal of Experimental Child Psychology, 71, 165-169.

Ceci, S. J., Fitneva, S. A., \& Williams, W. M. (2010). Representational constraints on the development of memory and metamemory: A developmental-representational theory. Psychological Review, 117, 464-495.

Ceci, S. J., \& Friedman, R. D. (2000). The suggestibility of children: Scientific research and legal implications. Cornell Law Review, 86, 34-108.

Ceci, S. J., Papierno, P. D., \& Kulkofksy, S. (2007). Representational constraints on children's suggestibility. Psychological Science, $18,503-509$.

Ceci, S. J., Ross, D. F., \& Toglia, M. P. (1987). Suggestibility in children's memory: Psycholegal implications. Journal of Experimental Psychology: General, 116, 38-49. 
Committee on the Judiciary of the House of Representatives. (2006). Federal rules of evidence. Washington, DC: United States Government Printing Office.

Connolly, D. A., \& Price, H. L. (2006). Children's suggestibility for an instance of a repeated event versus a unique event: The effect of degree of association between variable details. Journal of Experimental Child Psychology, 93, 207-223.

Deese, J. (1959). On the prediction of occurrence of certain verbal intrusions in free recall. Journal of Experimental Psychology, 58, 17-22.

Dewhurst, S. A., Pursglove, R. C., \& Lewis, C. (2007). Story contexts increase susceptibility to the DRM illusion in 5-year-olds. Developmental Science, 10, 374-378.

Dewhurst, S. A., \& Robinson, C. A. (2004). False memories in children: Evidence for a shift from phonological to semantic associations. Psychological Science, 15, 782-786.

Doris, J. (Ed.). (1991). The suggestibility of children's recollections. Washington, D.C.: American Psychological Association.

Fazio, L. K., \& Marsh, E. J. (2008). Older, not younger, children learn more false facts from stories. Cognition, 106, 1081-1089.

Fernandez-Dols, J. M., Carrera, P., Barchard, K. A., \& Gacitua, M. (2008). False recognition of facial expressions of emotion: Causes and implications. Emotion, 8, 530-539.

Foley, M. A., \& Johnson, M. K. (1985). Confusions between memories for performed and imagined actions: A developmental comparison. Child Development, 56, 1145-1155.

Foley, M. A., Johnson, M. K., \& Raye, C. L. (1983). Age-related changes in confusion between memories for thoughts and memories for speech. Child Development, 54, 51-60.

Gallo, D. A. (2004). Using recall to reduce false recognition: Diagnostic and disqualifying monitoring. Journal of Experimental Psychology. Learning, Memory, and Cognition, 30, 120-128.

Gallo, D. A. (2006). Associative illusions of memory: False memory research in DRM and related tasks. New York: Psychology Press.

Gallo, D. A. (2010). False memories and fantastic beliefs: 15 years of the DRM illusion. Memory \& Cognition.

Gallo, D. A., Roberts, M. J., \& Seamon, J. G. (1997). Remembering words not presented in lists: Can we avoid creating false memories? Psychonomic Bulletin \& Review, 4, 271-276.

Ghetti, S., Qin, J., \& Goodman, G. S. (2002). False memories in children and adults: Age, distinctiveness, and subjective experience. Developmental Psychology, 38, 705-718.

Glaser, R. E., \& Resnick, L. B. (1972). Instructional psychology. Annual Review of Psychology, 23, 207-276.

Grossman, L., \& Eagle, M. (1970). Synonymity, antonymity, and association in false recognition responses. Journal of Experimental Psychology, 83, 244-248.

Goodman, G. S., \& Schaaf, J. M. (1997). Over a decade of research on children's eyewitness testimony: What have we learned? Where do we go from here? Applied Cognitive Psychology, 11, S5-S20.

Gudjonsson, G. H. (1984). A new scale of interrogative suggestibility. Personality and Individual Differences, 5, 303-314.

Holliday, R. E., Brainerd, C. J., \& Reyna, V. F. (2008). Recall of details never experienced: Effects of age, repetition, and semantic cues. Cognitive Development, 23, 67-78.

Holliday, R. E., Brainerd, C. J., \& Reyna, V. F. (2010). Developmental reversals in false memory: Now you see them, now you don't. Developmental Psychology.

Holliday, R. E., \& Weekes, B. S. (2006). Dissociated developmental trajectories for semantic and phonological false memories. Memory, 14, 264-636.

Horvath, F., \& Meesig, R. (1996). The criminal investigation process and the role of forensic evidence: A review of empirical findings. Journal of Forensic Sciences, 41, 963-969.

Horvath, F., \& Meesig, R. (1998). A content analysis of textbooks on criminal investigation: An evaluative comparison to empirical research findings on the investigative process and the role of forensic evidence. Journal of Forensic Sciences, 43, 133-140.

Howe, M. L. (2005). Children (but not adults) can inhibit false memories. Psychological Science, 16, 927-931.

Howe, M. L. (2006). Developmentally invariant dissociations in children's true and false memories: Not all relatedness is created equal. Child Development, 77, 1112-1123.

Howe, M. L. (2007). Children's emotional false memories. Psychological Science, 18, 856-860.

Howe, M. L. (2008). Visual distinctiveness and the development of children's false memories. Child Development, 77, 1112-1123.

Howe, M. L., Cicchetti, D., Toth, S. L., \& Cerrito, B. M. (2004). True and false memories in maltreated children. Child Development, $75,1402-1417$

Howe, M. L., Gagnon, N., \& Thouas, L. (2007). Development of false memories in bilingual children and adults. Journal of Memory and Language, 58, 669-681.

Howe, M. L., Wimmer, M. C., Gagnon, N., \& Plumpton, S. (2009). An associative-activation theory of children's and adults' memory illusions. Journal of Memory and Language, 60, 229-251.

Khanna, M. M., \& Cortese, M. J. (2009). Children and adults are differentially affected by presentation modality in the DRM paradigm. Applied Cognitive Psychology, 23, 859-877.

Kimball, D. R., \& Bjork, R. A. (2002). Influences of intentional and unintentional forgetting on false memories. Journal of Experimental Psychology: General, 131, 116-130.

Lampinen, J. M., Leding, J. K., Reed, K. B., \& Odegard, T. N. (2006). Global gist extraction in children and adults. Memory, 14, 952964.

Loftus, E. F. (1975). Leading questions and eyewitness report Cognitive Psychology, 7, 560-572.

Lyons, K. E., Ghetti, S., \& Cornoldi, C. (2010). Age differences in the contribution of recollection and familiarity to false-memory formation: A new paradigm to examine developmental reversals. Developmental Science, 13, 355-362.

Madan, C. R., Glaholt, M. G., \& Caplan, J. B. (2010). The influence of item properties on association-memory. Journal of Memory and Language, 63, 46-63.

Marche, T. A., Brainerd, C. J., \& Reyna, V. F. (2010). Distinguishing true from false memories in forensic contexts: Can phenomenology tell us what is real? Applied Cognitive Psychology.

McDermott, K. B. (1996). The persistence of false memories in list recall. Journal of Memory and Language, 35, 212-230.

McGough, L. S. (1993). Child witnesses: Fragile voices in the American legal system. New Haven, CT: Yale University Press.

Metzger, R. L., Warren, A. R., Price, J. D., Reed, A. W., Shelton, J., \& Williams, D. (2008). Do children "DRM" like adults? False memory production in children. Developmental Psychology, 44, 169-181.

Nelson, D. L., McEvoy, C. L., \& Schreiber, T. A. (1999). The University of South Florida word association, rhyme, and word fragment norms. Unpublished manuscript. Tampa: University of South Florida.

Neoh, J., \& Mellor, D. (2009). Professional issues related to allegations and assessment of child sexual abuse in the context of family court litigation. Psychiatry, Psychology, and Law, 16, 303-321.

Obrzut, J., \& Hynd, G. (Eds.). (1991). Advances in the neuropsychology of learning disabilities. New York: Academic Press.

Odegard, T. N., Cooper, C. M., Lampinen, J. M., Reyna, V. F., \& Brainerd, C. J. (2009). Children's eyewitness memory for multiple real-life events. Child Development, 80, 1877-1890.

Odegard, T. N., Holliday, R. E., Brainerd, C. J., \& Reyna, V. F. (2008). Attention to global-gist processing eliminates age effects in false memories. Journal of Experimental Child Psychology, 99, 96-113.

Otgaar, H., \& Smeets, T. (2010). Adaptive memory: Survival processing increases both true and false memory in adults and 
children. Journal of Experimental Psychology. Learning, Memory, and Cognition, 36, 1010-1016.

Paivio, A. (1969). Mental imagery in associative learning and memory. Psychological Review, 76, 241-263.

Paivio, A. (1979). Imagery and verbal processes. Hillsdale, NJ: Erlbaum.

Patterson, T., \& Pipeb, M. E. (2009). Exploratory assessments of child abuse: Children's responses to interviewer's questions across multiple interview sessions. Child Abuse \& Neglect, 33, 490-504.

Paz-Alonso, P. M., Ghetti, S., Donohue, S. E., Goodman, G. S., \& Bunge, S. A. (2008). Neurodevelopmental correlates of true and false recognition. Cerebral Cortex, 18, 2208-2216.

Petersen, R. C. (2004). Mild cognitive impairment as a diagnostic entity. Journal of Internal Medicine, 256, 183-194.

Poole, D. A., \& Lamb, M. E. (1998). Investigative interviews of children. Washington, DC: American Psychological Association.

Principe, G. F., Guiliano, S., \& Root, C. (2008). Rumor mongering and remembering: How rumors originating in children's inferences can affect memory. Journal of Experimental Child Psychology, 99, $135-155$.

Qin, J., Ogle, C. M., \& Goodman, G. S. (2008). Adults' memories of childhood: True and false reports. Journal of Experimental Psychology. Applied, 14, 373-391.

Reyna, V. F., \& Brainerd, C. J. (1995). Fuzzy-trace theory: An interim synthesis. Learning and Individual Differences, 7, 1-75.

Reyna, V. F., \& Kiernan, B. (1994). The development of gist versus verbatim memory in sentence recognition: Effects of lexical familiarity, semantic content, encoding instructions, and retention interval. Developmental Psychology, 30, 178-191.

Reyna, V. F., \& Kiernan, B. (1995). Children's memory and interpretation of psychological metaphors. Metaphor and Symbolic Activity, 10, 309-331.

Reyna, V. F., Mills, B., Estrada, S., \& Brainerd, C. J. (2007). False memory in children: Data, theory, and legal implications. In M. P. Toglia, J. D. Read, D. F. Ross, \& R. C. L. Lindsay (Eds.), Handbook of eyewitness psychology (pp. 479-507). Mahwah, NJ: Erlbaum.

Robinson, K. J., \& Roediger, H. L. (1997). Associative processes in false recall and recognition. Psychological Science, 8, 231-237.

Roediger, H. L., III, \& McDermott, K. B. (1995). Creating false memories: Remembering words not presented on lists. Journal of Experimental Psychology. Learning, Memory, and Cognition, 21, 803-814.

Roediger, H. L., III, W. J. M., McDermott, K. B., \& Gallo, D. A. (2001). Factors that determine false recall: A multiple regression analysis. Psychonomic Bulletin \& Review, 8, 385-405.

Ross, D. F., Marsil, D. F., Benton, T. R., Hoffman, R., Warren, A. R., Lindsay, R. C. L., et al. (2006). Children's susceptibility to misidentifying a familiar bystander from a lineup: When younger is better. Law and Human Behavior, 30, 249-257.

Rubin, D. C., \& Talarico, J. M. (2009). A comparison of dimensional models of emotion: Evidence from emotions, prototypical events, autobiographical memories, and words. Memory, 8, 802-808.
Russell, W. A., \& Jenkins, J. J. (1954). The complete Minnesota norms for responses to 100 words from the Kent-Rosanoff word association test (Tech. Rep. No. 11, Contract N8 ONR 66216, Office of Naval Research). Minneapolis: University of Minnesota.

Schacter, D. L., Israel, L., \& Racine, C. (1999). Suppressing false recognition in younger and older adults: The distinctiveness heuristic. Journal of Memory and Language, 40, 124.

Scullin, M. H., \& Ceci, S. J. (2001). A suggestibility scale for children. Personality and Individual Differences, 30, 843-856.

Sommers, M. S., \& Lewis, B. P. (1999). Who really lives next door: creating false memories with phonological neighbors. Journal of Memory and Language, 40, 83-108.

Sugrue, K., \& Hayne, H. (2006). False memories produced by children and adults in the DRM paradigm. Applied Cognitive Psychology, 20, 625-631.

Sugrue, K., Strange, D., \& Hayne, H. (2009). False memories in the DRM paradigm age-related differences in lure activation and source monitoring. Experimental Psychology, 56, 354360 .

Thapar, A., \& McDermott, K. B. (2001). False recall and false recognition induced by presentation of associated words: Effects of retention interval and level of processing. Memory \& Cognition, 29, 424-432.

Toglia, M. P., \& Battig, W. F. (1978). Handbook of semantic word norms. Hillsdale, NJ: Erlbaum.

Toglia, M. P., Neuschatz, J. S., \& Goodwin, K. A. (1999). Recall accuracy and illusory memories: When more is less. Memory, 7, 233-256.

Weekes, B. S., Hamilton, S., Oakhill, J., \& Holliday, R. E. (2007). False recollection in children with reading comprehension difficulties. Cognition, 106, 222-233.

Wells, G. L., Small, M., Penrod, S., Malpass, R. S., Fulero, S. M., \& Brimacombe, C. A. E. (1998). Eyewitness identification procedures: Recommendations for lineups and photospreads. Law and Human Behavior, 23, 603-648.

Wimmer, M. C., \& Howe, M. L. (2010). Are children's memory illusions created differently from those of adults? Evidence from levels-of-processing and divided attention paradigms. Journal of Experimental Child Psychology.

Wu, L. L., \& Barsalou, L. W. (2009). Perceptual simulation in conceptual combination: Evidence from property generation. Acta Psychologica, 132, 173-189.

Portions of the research were supported by National Institutes of Health Grant 1RC1AG036915-01 to the first and second authors. 